\title{
Effects of acute exposure to heavy fuel oil from the Prestige spill on a seabird
}

\author{
Carlos Alonso-Alvarez ${ }^{\mathrm{a}, *}$, Cristobal Pérez ${ }^{\mathrm{b}}$, Alberto Velando ${ }^{\mathrm{b}}$ \\ ${ }^{a}$ Unidad de Ecología, Instituto de Investigación en Recursos Cinegéticos, IREC (CSIC, UCLM, JCCM), \\ Ronda de Toledo s/n, Ciudad Real 13005, Spain

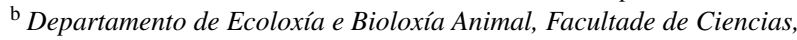 \\ Universidade de Vigo, Pontevedra, Spain
}

Received 25 April 2007; received in revised form 8 June 2007; accepted 8 June 2007

\begin{abstract}
Large quantities of petroleum products are released into the marine environment as result of tanker wrecks. Such catastrophic events have a dramatic impact on marine ecosystems, affecting a broad range of species. Seabirds are placed at the uppermost trophic level of the marine food chain. Therefore, important toxic effects are expected in these organisms. The recent Prestige oil spill gave the opportunity to test this. A previous study reported that yellow-legged gulls (Larus michahellis) breeding in the oiled area (17 months after the spill) showed differences both in plasma biochemistry and in the total circulating levels of polycyclic aromatic hydrocarbons (TPAHs) in blood regard to gulls sampled in clean areas. In the present study, wild yellow-legged gulls were fed with heavy fuel oil from the Prestige oil spill (P-gulls) and compared with control gulls (C-gulls) fed only with the vehicle (vegetable oil). Consistent with the cited previous findings, gulls fed with fuel oil showed reduced glucose and inorganic phosphorus levels in plasma, as well as a trend to significantly reduced creatinine values. In addition, glucose concentration was negatively related to TPAH levels. Males but not females fed with fuel oil showed higher plasma activity of asparatate aminotransferase (AST) than controls. With regard to plasma activity of gamma-glutamyl transferase (GGT), the results were opposite to the previous study. The GGT activity increased in C-females, apparently to meet with increased liver metabolism due to egg laying demands, but not in P-females. Differences to the previous study possibly reflect different adaptive responses of these enzymes to an acute short-term exposure to heavy fuel oil. Since the yellow-legged gull belongs to a complex of species widely distributed throughout the Northern hemisphere, the results as a whole might provide a tool for future evaluations of short- and long-term effects of oil spills on seabirds. Decreased glucose and inorganic phosphorus levels in plasma are expected in both short- and long-lasting exposures to fuel oil, whereas responses of AST and GGT enzymes would depend on both the sex of individuals and the temporal pattern of exposure.
\end{abstract}

(C) 2007 Elsevier B.V. All rights reserved.

Keywords: Heavy fuel oil ingestion; Glucose; Larus michahellis; Liver damage; Polycyclic aromatic hydrocarbons; Prestige oil spill; Yellow-legged gulls

\section{Introduction}

Different compounds present in petroleum products (such as polycyclic aromatic hydrocarbons [PAHs]; i.e. list in Keith and Telliard, 1979) are able to induce carcinogenic and immunotoxic effects as well as endocrine disruption in vertebrates (e.g. Gelboin and Ts'o, 1981; Nicolas, 1999; Reynaud and Deschaux,

Abbreviations: AST, asparatate aminotransferase; CV, coefficient of variability; df, degrees of freedom; GGT, gamma-glutamyl transferase; HPLC, high performance liquid chromatography; iP, inorganic phosphorus; TPAH, total polycyclic aromatic hydrocarbons; SE, standard error

* Corresponding author. Tel.: +34 926295450; fax: +34 926295451.

E-mail address: carlos.alonso@uclm.es (C. Alonso-Alvarez).
2006). Large quantities of petroleum products are released into the marine environment as result of tanker wrecks. Such catastrophic events have a dramatic impact on marine ecosystems, affecting a broad range of organisms, including seabirds (e.g. Peterson, 2001; Velando et al., 2005a,b). One of the last examples of a large marine oil spill took place in November 2002 when the supertanker Prestige sank in the Galician coast (NW Spain). The tanker spilled between 40,000 and 63,000 tonnes of heavy fuel oil into the Atlantic Ocean (e.g. Marcos et al., 2004; Diez et al., 2007), causing pollution from Portugal to France. The Prestige oil spill was the biggest catastrophe of its type in Europe and thousands of seabirds died in the following months (Camphuysen et al., 2002; Martínez-Abraín et al., 2006). Moreover, toxic compounds present in the Prestige oil spill, such as 
PAHs, are currently being detected in the marine food chain (e.g. Fernandez et al., 2006a,b; Laffon et al., 2006; Morales-Caselles et al., 2006; Ordas et al., 2007).

Seabirds are placed at the uppermost trophic level of the marine food chain. Important toxic effects of the petroleum products would be therefore expected in these organisms. In the past, many studies have reported damaging effects of exposure to petroleum products in seabirds after oil spills (e.g. Newman et al., 1999; Seiser et al., 2000; Golet et al., 2002; Balseiro et al., 2005). However, as far as we know, only one study on seabirds has determined the presence of PAHs in the organism, exploring the relationship between the total blood circulating levels of PAHs (TPAH) and the health status of individuals (Alonso-Alvarez et al., 2007). That study was carried out on the most common seabird of Galician coasts, the yellow-legged gull (Larus michahellis). The species was used to monitor the impact of the Prestige oil spill on the marine ecosystem. The previous knowledge on the plasma biochemistry of this particular seabird (e.g. Alonso-Alvarez and Ferrer, 2001; Alonso-Alvarez and Velando, 2003; Alonso-Alvarez, 2005) allowed the interpretation of the results, which suggested different sub-lethal effects associated to a long-term exposure to fuel oil. Thus, birds sampled in oiled areas showed reduced levels of glucose, inorganic phosphorus (iP), total protein and creatinine as well as higher levels of two aminotransferases, namely gamma-glutamyl transferase (GGT) and aspartate aminotransferase (AST) (Alonso-Alvarez et al., 2007).

In birds, high GGT levels in blood are commonly used as an index of liver disease, as well as damages in biliary ducts and renal epithelium (reviewed by Lewandowski et al., 1986; Hochleithner, 1994 and Harr, 2002). Meanwhile, high AST concentration in blood would be indicative of hepatocellular disease in birds (Brugère-Picoux et al., 1987; Harr, 2002). Both GGT and AST enzymes are involved in the transamination of glucogenic amino acids (i.e. glutamate and aspartate, respectively; Stevens, 1996) in order to produce glucose (e.g. Stevens, 1996). Therefore, changes on these parameters would not only support the idea of liver damages, but also explain the decrease in glucose levels in the earlier study (i.e. Alonso-Alvarez et al., 2007). Moreover, the study reported positive correlations between the total blood concentrations of PAHs (TPAH) and a number of the analysed substances. Although such correlations do not imply causation, the results are suggestive of an effect of these particular compounds on seagull physiology. In summary, the results as a whole suggested fuel-oil induced damages on vital organs (i.e. liver and kidney). However, an experimental demonstration of these effects was still necessary.

Here, we have carried out such an experiment. Wild yellowlegged gulls were experimentally fed with heavy fuel oil from the Prestige oil spill and compared with control gulls fed only with vehicle (i.e. vegetable oil). The study provided the opportunity to compare the sub-lethal effects of a long-term exposure to toxic compounds in the oil spill (i.e. Alonso-Alvarez et al., 2007) with the effects induced by a short-term acute exposure in a vertebrate species. The same biochemical parameters were analysed as in the earlier correlational study (Alonso-Alvarez et al., 2007). In addition, the total concentration of 15 PAHs found in the Prestige heavy fuel oil (Bosch, 2003; CSIC, 2003) was determined in the red cell fraction of blood.

\section{Materials and methods}

\subsection{Experimental procedure}

Thirty-one yellow-legged gull couples were randomly chosen at their breeding colony (Illas Cíes, Galicia, NW Spain). This population suffered the impact of the Prestige oil spill in 2002 (Alonso-Alvarez et al., 2007). Twelve breeding pairs chosen at random were daily fed with $0.04 \mathrm{ml}$ of unweathered heavy fuel oil from the Prestige oil spill (petrol-fed birds, "Pbirds"), kindly provided by Instituto Español de Oceanografía under the control of the Spanish Technical Bureau of Marine Spills (otvm.uvigo.es). In the heavy fuel oil provided to birds, the concentration of the 15 PAHs (described below) was $17.75 \mu \mathrm{g} / \mathrm{mL}$.

Ethical considerations were taken into account in the experiment design to minimize the damage caused by fuel oil while still eliciting a measurable response. To avoid provoking unnecessary damage to the gulls and to keep the number of subjects needed as low as possible (Still, 1982), we chose an amount of fuel oil ( $0.3 \mathrm{ml}$ in 7 days) well below the dosage used in previous experiments (e.g. Butler and Lukasiewicz, 1979; Leighton et al., 1985).

Fuel oil was mixed with vegetable oil and placed on a slice of bread, which was hidden under vegetation and close to the nest ( $50 \mathrm{~cm}$ approximately) to avoid the risk of being eaten by non-target birds. Yellow-legged gulls are territorial, defending aggressively several meters around their nest site (AlonsoAlvarez, 2001; Alonso-Alvarez and Velando, 2001). Moreover, a previous experience providing food in the same way and registering behavior of gulls around the territory reported that no food item was stolen by other birds (Pérez et al., 2006). The other 19 pairs (control birds, "C-birds") were fed in the same way, but the bread did not contain fuel oil, but only vegetable oil. There were no differences in body size (i.e. tarsus length or head length) between gulls assigned to each group ( $p$-values $>0.20$ ). All gulls were fed from April 26 (just before the egg-laying period in the population) to the time when the clutch was completed (mean, range: 2.8, 1-3 eggs). Fuel oil diet was, however, restricted to seven consecutive days (until May 3 ). From the end of the 7-day period to the end of the egg-laying period all birds received bread with only vegetable oil (mean \pm SE: $9.2 \pm 0.98$ days, range 1-21 days). There was no difference between treatments in the number of days elapsed from the start of feeding to the end of egg-laying (complete feeding period) $\left(F_{1,29}=0.29\right.$, $p=0.597$; means \pm S.E.: $9.84 \pm 1.1$ days and $8.75 \pm 1.88$ days for C- and P-gulls, respectively).

One of the members of the couple was randomly captured at their nest site during incubation (10 C-females, $8 \mathrm{P}$-females, 9 $\mathrm{C}$-males and 4 P-males). A blood sample (about $1.5 \mathrm{~mL}$ ) was immediately taken from the ulnar vein with a heparinized $25 \mathrm{G}$ needle. Blood was then transferred to plastic tubes and microcapillaries filled from them. Both tubes and filled microcapillaries were maintained cooled in ice boxes $\left(4^{\circ} \mathrm{C}\right)$, and centrifuged at 
the end of the day. Plasma and blood cells (pellet) were separately frozen in liquid nitrogen $\left(-196^{\circ} \mathrm{C}\right)$. Hematocrit values were daily determined from centrifuged microcapillaries.

Several morphometric measures including the head and tarsus length (to $1 \mathrm{~mm}$ ) were measured on each bird. Body mass was also determined (to $1 \mathrm{~g}$ ). The tarsus length allowed sexing birds by means of a discriminant function (Bosch, 1996). The number of days elapsed from the end of the laying to the capture date did not differ between groups $\left(F_{1,29}=1.02, p=0.321\right.$; means \pm S.E.: $8.68 \pm 1.1$ days and $10.8 \pm 2.1$ days for $C$ - and P-gulls, respectively).

\subsection{TPAH levels}

Fifteen of the most toxic polycyclic aromatic hydrocarbons (PAHs), according to U.S. Environmental Protection Agency (EPA) data (Keith and Telliard, 1979) and present in the Prestige heavy fuel oil (CSIC, 2003), were measured in the red blood cell fraction (pellet). The PAHs analysed were acenaphthene, anthracene, benz(a)anthracene, benzo(a)pyrene, benzo $(b+j)$ fluoranthene, benzo(g,h,i)perylene, benzo $(k)$ fluoranthene, chrysene, dibenz(a,h)anthracene, fluorene, fluoranthene, indeno(1,2,3-c-d)pyrene, naphthalene, phenanthrene and pyrene. To estimate the individual degree of oil contamination, the sum of concentrations from all these hydrocarbons was used as a variable (TPAH level).

The concentrations of PAHs were determined by high performance liquid chromatography (HPLC). After microwave extraction with a mixture of acetone:hexane $1: 1$, the extract was cleaned-up using a deactivated alumina column with hexane as eluant. The PAHs were determined by HPLC coupled to a wavelength programmable fluorescence detector (ViñasDiéguez, 2002). The method used certified quality controls from the National Institute of Standards and Technology (Gaithersburg, USA; references NIST SRM 1647d and 2977). Moreover, the method was involved in the "Prestige, 2004 Intercalibra- tion Trial" organized by the Instituto Español de Oceanografía (www.ieo.es).

\subsection{Biochemical measurements from plasma}

The measurements were carried out using a spectrophotometer (A-25, Biosystems SA, Barcelona), and commercial kits and certified controls from Biosystems (Biosystems SA, Barcelona). The analyzed parameters were (method in parenthesis): AST activity (NADH-method), calcium concentration (arsenaze III), cholesterol concentration (cholesterol oxidase), creatinine concentration (alkaline picrate), GGT activity (carboxy substrate), glucose concentration (glucose oxidase), inorganic phosphorus concentration (phospho-molybdate reaction), total protein concentration (biuret reaction) and uric acid concentration (uricase method). The within-assay coefficient of variation (CV) for all these parameters ranged between $0.4 \%$ and $2.9 \%$. The analyses were carried out in the same assay session. The experimental groups were alternated in the reader plate. There was not enough sample volume for all tests in all the samples, and thus degrees of freedom showed in results (Table 1) could vary.

\subsection{Breeding output}

Reproduction was monitored by regular visits to the colony. Egg width and length were measured with a caliper to the nearest $0.01 \mathrm{~mm}$. We calculated egg volume using the function $0.51 \times$ length $\times(\text { width })^{2}$, proposed by Hoyt (1979)

\subsection{Statistical analyses}

We tested differences between P- and C-birds by running several ANCOVA models including the experimental treatment and the sex as fixed factors, testing its interaction. Additionally, other potentially confounding factors and covariates were introduced in the models in order to control for individual variability.

Table 1

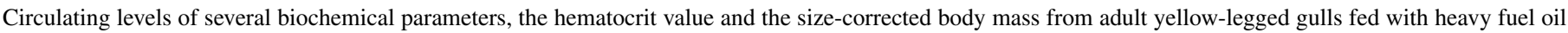
from the Prestige oil spill or fed with vehicle only (controls)

\begin{tabular}{|c|c|c|c|c|c|c|c|}
\hline \multirow[t]{2}{*}{ Parameter } & \multicolumn{2}{|l|}{ Control } & \multicolumn{2}{|c|}{ Petrol-fed } & \multicolumn{3}{|c|}{ Treatment effect } \\
\hline & Mean & S.E. & Mean & S.E. & $F$ & d.f. & $p$ \\
\hline Glucose (mg/dL) & 471.8 & 10.48 & 441.7 & 20.96 & 6.02 & 1.25 & $0.010^{\mathrm{a}}$ \\
\hline iP (mg/dL) & 2.99 & 0.22 & 2.45 & 0.36 & 6.51 & 1.25 & $0.009^{\mathrm{a}}$ \\
\hline Creatinine (mg/dL) & 0.79 & 0.02 & 0.56 & 0.05 & 2.49 & 1.28 & $0.063^{\mathrm{a}}$ \\
\hline $\mathrm{Ca}(\mathrm{mg} / \mathrm{dL})$ & 13.22 & 0.39 & 12.46 & 0.59 & 3.88 & 1.26 & 0.274 \\
\hline Uric acid (mg/dL) & 6.52 & 1.05 & 4.67 & 0.47 & 1.87 & 1.28 & 0.183 \\
\hline GGT (U/L) & 15.30 & 4.40 & 5.87 & 3.92 & 1.80 & 1.24 & 0.192 \\
\hline AST (U/L) & 289 & 19.8 & 310.8 & 27.3 & 1.74 & 1.24 & 0.200 \\
\hline Cholesterol (mg/dL) & 410.9 & 19.3 & 420.8 & 16.99 & 0.13 & 1.28 & 0.722 \\
\hline Total protein $(\mathrm{g} / \mathrm{dL})$ & 52.76 & 3.03 & 51.5 & 2.01 & 0.37 & 1.28 & 0.547 \\
\hline Hematocrit (\%) & 44.11 & 0.80 & 43.67 & 1.24 & 0.10 & 1.29 & 0.751 \\
\hline Male size-corrected body mass (residuals) ${ }^{\mathrm{b}}$ & -0.15 & 0.33 & 0.18 & 0.14 & 0.70 & 1.9 & 0.426 \\
\hline Female size-corrected body mass (residuals) ${ }^{\mathrm{b}}$ & 0.01 & 0.38 & -0.01 & 0.66 & 0.48 & 1.14 & 0.499 \\
\hline
\end{tabular}

The effect of the treatment from ANCOVA models is also shown. Other significant factors and covariates are described in results.

a One-tailed $p$-values established from a priori predictions (see Section 2).

b Size-corrected body masses were standardized residuals from the model including tarsus and head length as covariates (always $p<0.05$ ). 
We always started from the saturated model with all factors and covariates, removing non-significant terms by a backward stepwise procedure. Covariates were: body mass and body size of gulls, total egg volume of the clutch and the number of days elapsed from the beginning of the treatment to the end of egglaying (complete feeding period). In addition, the influence of clutch size was tested as a fixed factor with three levels (1-3 eggs).

The tarsus and head length of adults were also added as covariates when analysing size-corrected body mass (e.g. García-Berthou, 2001; Stevenson and Woods, 2006). Since adult body mass follows a bimodal distribution (i.e. yellowlegged gulls are sexually dimorphic in size; Bosch, 1996), the analyses on this variable were performed separately for each sex.

The interaction between circulating levels of TPAH and the experimental treatment was also tested in order to know if the PAHs acquired from the experimental diet or from the environment correlated with different responses.

In order to avoid type II errors due to the reduced sample size (see ethical considerations above), we used one-tailed $p$ values in those analyses where an a priori prediction was clear, as recommended in studies which involve manipulations that are potentially detrimental to the animals (Still, 1982). Thus, we predict that P-birds would show a higher TPAH level in blood than controls (above). Moreover, we predicted some differences between treatments following results in the previous study on the impact of the Prestige oil spill on yellow-legged gulls (Alonso-Alvarez et al., 2007). In this way, we predicted lower glucose, total protein, creatinine and phosphorus levels and higher AST activities in P-birds. Similarly, we predicted higher GGT activities in P-females (i.e. Alonso-Alvarez et al., 2007). Calcium concentrations and AST activities were logtransformed whereas creatinine concentrations were square root transformed to meet the normality requirements for parametric analyses. SAS statistical software was used (version 8.2; SAS Institute, 2001). DMS tests were used for pairwise post hoc comparisons. Results are given as means \pm S.E.

\section{Results}

\subsection{TPAH in blood}

As expected, TPAH values of P-gulls were higher than TPAH values of C-gulls $(75.79 \pm 9.13$ and $56.42 \pm 5.38 \mathrm{ng} / \mathrm{g}$, respectively; $\left.F_{1,29}=3.80, p=0.031\right)$. Neither the sex of the bird nor the treatment $\times$ sex interaction showed significant effects (both $p$ 's $>0.75)$.

\subsection{Breeding output, body mass and hematocrit variability}

The date of laying of the first egg did not differ between treatments $\left(F_{1,29}=0.14, p=0.716\right.$; Julian calendar: $127.8 \pm 1.1$ and $127 \pm 1.9$ days, for $\mathrm{C}$ - and P-gulls, respectively). Neither clutch nor the total volume of eggs $\left(F_{1,29}=0.23, p=0.634 ; 212 \pm 8.5\right.$ and $205 \pm 15.8 \mathrm{~cm}^{3}$, for C- and P-gulls, respectively) differed between experimental groups. Neither the size-corrected body mass (both sexes) nor the hematocrit value showed differences between the treatments (Table 1).

\subsection{Effects on plasma parameters}

Gulls experimentally fed with heavy fuel oil showed significantly lower plasma concentrations of glucose and iP than controls (Table 1 and Fig. 1). Creatinine concentrations also tended to be lower in fuel oil supplemented gulls, but the difference was not significant (Table 1 and Fig. 1; sex $\times$ treatment interaction was not significant: $p>0.20$ ). In the case of plasma glucose levels, the interaction between experimental group and the concentration of circulating PAHs was significant $\left(F_{1,25}=6.64, p=0.016\right)$. Thus, whereas TPAH did not correlate with glucose levels in controls $(r=+0.16, p=0.531)$, a clear negative relationship was present in P-gulls $(r=-0.66$, $p=0.019$; Fig. 2). Meanwhile, when the clutch size was retained in the model testing variability in iP levels $\left(F_{1,25}=8.39\right.$, $p=0.002)$, phosphorus values decreased with increasing clutch size $(5.78 \pm 0.01,2.69 \pm 0.42$ and $2.65 \pm 0.19 \mathrm{mg} / \mathrm{dL}$, for $1-, 2-$ and 3-egg clutches).

In the model on plasma calcium levels, the treatment $\times$ sex interaction was close to significance $\left(F_{1,24}=3.67, p=0.068\right.$; Fig. 1). Thus the effect of fuel-oil supplementation was evident in females but not in males. P-females showed lower calcium levels than $\mathrm{C}$-females $(11.8 \pm 0.73$ and $13.6 \pm 0.45 \mathrm{mg} / \mathrm{dL}$, respectively; $p=0.034)$, whereas males did not show any effect $(13.6 \pm 0.81$ and $12.8 \pm 0.56 \mathrm{mg} / \mathrm{dL}$ for $\mathrm{P}$ - and C-males, respectively; $p=0.490)$.

With regard to the enzymes, the effect of the experiment on AST activities was evident in males but not in females (sex $\times$ treatment, $F_{1,24}=4.58, p=0.043$; Fig. 1). Thus, males fed with petrol showed higher AST activities than controls $(p=0.041)$. However, P-male activities did not differ from those found in females $(p>0.37)$. The number of days from the beginning of the experimental feeding to the end of the egg laying (complete feeding period) correlated positively with AST activities $(r=+0.38, p=0.044)$ and was retained in the model on AST variability $\left(F_{1,24}=7.16, p=0.013\right)$. Meanwhile, GGT activity was significantly affected by the interaction between treatment and sex $\left(F_{1,24}=5.12, p=0.033\right)$, but in the opposite direction from that previously predicted (Fig. 1). Thus, $\mathrm{C}$-females clearly showed higher GGT activities than P-females $(p=0.009)$, whereas males from both groups did not differ $(p=0.558)$.

\section{Discussion}

Here we experimentally demonstrate that yellow-legged gulls exposed to the Prestige heavy fuel oil (in feed) showed reduced levels of glucose and inorganic phosphorus. Thus, the present findings agree with previous correlational results from yellowlegged gulls captured several months after the Prestige oil spill. In that time, gulls captured in oiled areas also showed lower glucose and inorganic phosphorus levels than gulls from unoiled areas (Alonso-Alvarez et al., 2007). Interestingly, the results also revealed sex-specific differences in sensitivity to heavy fuel oil 

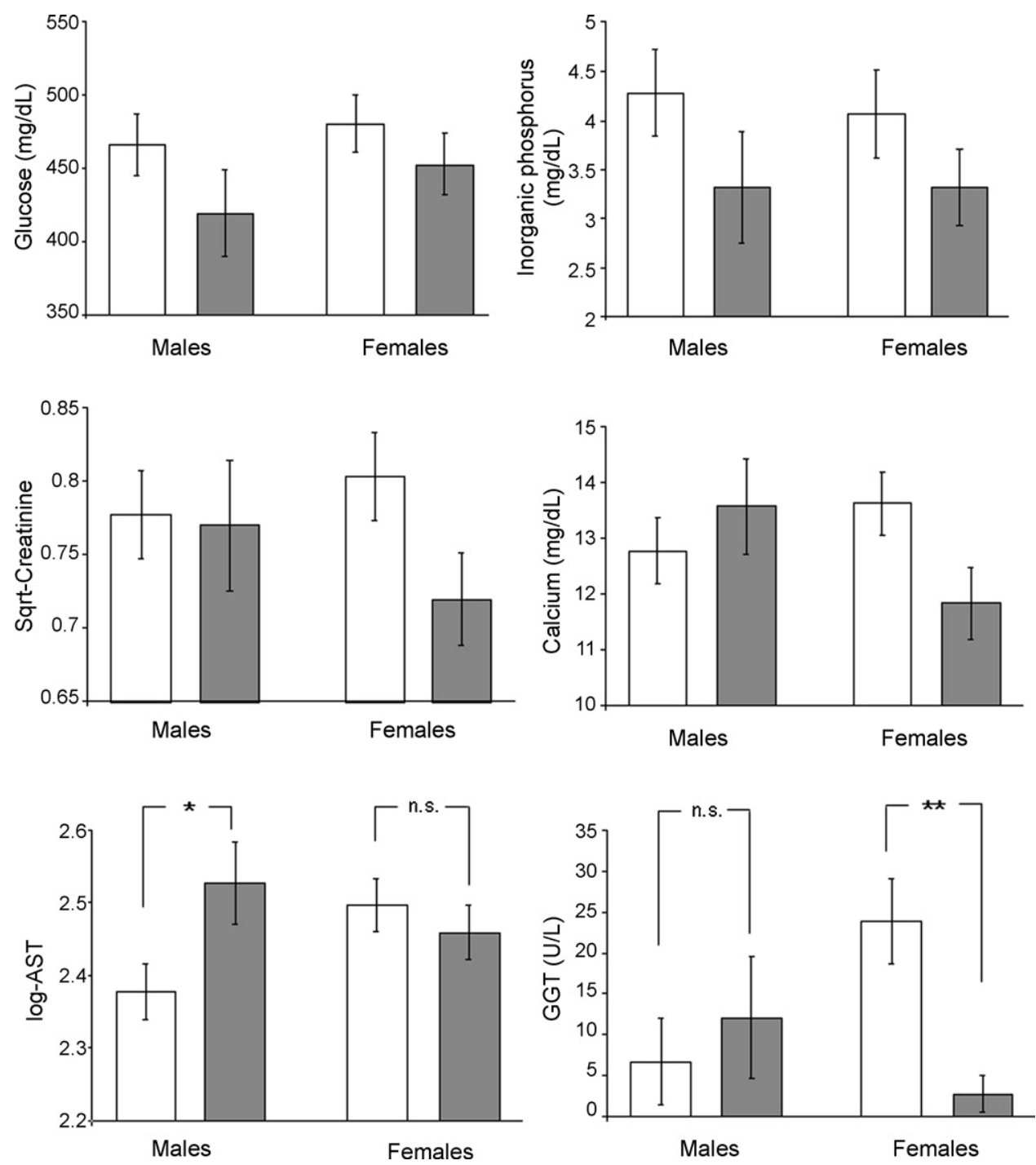

Fig. 1. Plasma levels of several biochemical parameters from yellow-legged gulls fed with vehicle (vegetable oil) or fed with vehicle plus heavy fuel oil from the Prestige oil spill (white and dark bars, respectively). Creatinine and AST values were transformed to meet with the normality assumption (Section 2). Data are separately presented for male and female individuals. The main effect of the treatment is nonetheless described in Table 1. Significance of within-sex post hoc comparisons is only represented for models showing a significant treatment $\times$ sex interaction (see Section $3 ;{ }^{*} p<0.05 ;{ }^{* *} p<0.010$; n.s.: non significant). Bars are means \pm S.E.

in other parameters (i.e. aminotransferase activities and calcium levels). Moreover, the findings highlight the differences of acute and long-term exposure to fuel oil on aminotransferase enzymes.

Low glucose levels as a result of ingestion of petroleum products have been also reported in American coots (Fulica americana) exposed to plumage oiling and crude oil intake after the Unocal-Metrolink spill (Newman et al., 2000). Thus, our results support the conclusion that petroleum products spilled on the marine environment are able to induce a decrease in circulating glucose levels in seabirds, not only after long-term exposures (i.e. 17 months; Alonso-Alvarez et al., 2007), but also after short episodes of ingestion. Nonetheless, Golet et al. (2002) reported higher glucose levels in blood from pigeon guillemots (Cepphus columbia) sampled in areas affected by the Exxon-Valdez oil spill. These authors suggested that the effect was due to an increased adrenal response because corticosterone, the hormone responsible of the physiological stress response, also showed high levels in these birds. However, contrary to this conclusion, other authors reported decreased adrenocortical response in oiled seabirds (i.e. Gorsline and Holmes, 1982).

Our results also suggest that PAHs could be the specific compounds responsible for such a decrease in glucose levels. Thus, TPAH values were negatively correlated to glucose concentration in P-gulls. Those birds supporting higher blood levels of PAHs also showed lower levels of glucose in plasma. Nonetheless, we must also consider that other toxic compounds present in the Prestige fuel oil could have contributed to the observed effects. This seems to be particularly probable when the oil is weathered (see e.g. Barron et al., 1999; Booth et al., 2007).

From a mechanistic perspective, the lower glucose levels in P-birds may suggest, at a first glance, a decrease in food intake. Circulating glucose concentration is tightly regulated because it is used as energy source for most tissues and cells (e.g. the central nervous system; Castellini and Rea, 1992). Here, the 


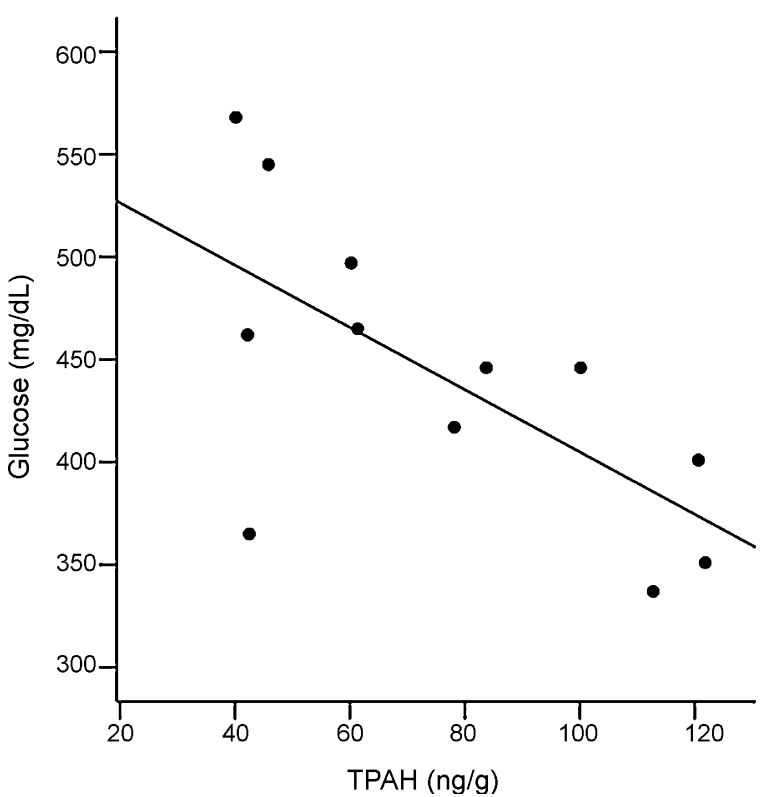

Fig. 2. The relationship between plasma glucose and total polycyclic aromatic hydrocarbon (TPAH) levels in the blood of yellow-legged gulls fed with heavy fuel oil from the Prestige oil spill.

glucose values of gulls from both experimental groups were higher than those reported in captive yellow-legged gulls fed ad libitum (Alonso-Alvarez and Ferrer, 2001) and than levels present in wild gulls sampled in the previous year (AlonsoAlvarez et al., 2007). Moreover, P-birds did not show lower body masses, which would have indicated reduced food intake. In the same way, they did not show lower hematocrit values, and hence, anaemia (e.g. Newman et al., 1999; Balseiro et al., 2005). The results agree with our previous study (Alonso-Alvarez et al., 2007) where gulls sampled in oiled areas showed reduced levels of glucose, but no effect on nutritional condition was detected. Thus, overall the results strongly suggest that glucose differences are not caused by reduced feeding. Instead, reduced glucose levels are probably due to the impact of TPAH or other toxic compounds present in fuel oil on glycogenic tissues. The liver is the main detoxification organ, but has also a pivotal role in glycogenesis (e.g. Stevens, 1996; Whittow, 2000). Hence, its malfunction could have led to reduced glucose synthesis and then reduced circulating glucose.

Liver malfunction could also explain differences in inorganic phosphorus concentrations. Avian embryos exposed to fluoranthene and benz $(k)$ fluoranthene, that is, two of the PAHs detected in our birds, showed liver necrosis and a decrease of alkaline phosphatase (ALP) activity (Kertesz and Hlubik, 2002). ALP is involved in phosphorus metabolism (Whittow, 2000). Since ALP is produced by liver, kidney, intestines and bones (Lewandowski et al., 1986; Hochleithner, 1994), any toxin acting on any of these tissues could potentially affect its activity, and consequently, iP levels. Studies analysing both acute and chronic exposures of seabirds to crude or fuel oil reported decreased iP concentrations. Thus, reduced iP levels have been reported in female mallards (Anas platyrhynchos) experimentally fed with crude oil (Stubblefield et al., 1995) and on pigeon guillemots sam- pled in the Exxon-Valdez oiled sites seven years after the spill (Golet et al., 2002). Meanwhile, the apparent impact of fuel oil on female calcium levels could be associated to the effort of eggshell production. Accordingly, Stubblefield et al. (1995) detected decreased levels of plasma calcium in female but not male mallards fed with crude oil, as well as reduced eggshell thickness.

Moreover, gulls fed with fuel oil also showed a trend to significantly lower creatinine levels. A significant difference in the same direction was observed between gulls sampled in oiled and unoiled sites (Alonso-Alvarez et al., 2007). Creatinine is produced in phosphocreatine catabolism, which is induced by creatine kinase to produce energy for the muscle activity (Wyss and Kaddurah-Daouk, 2000). Captive yellow-legged gulls maintained in a reduced space had lower values than those observed in the present study (Alonso-Alvarez and Ferrer, 2001). Thus, low creatinine levels could indicate decreased muscular metabolism. Otherwise, reduced creatinine levels could be associated with a reduced rate of glomerular filtration in kidneys, as deducted from bibliography in humans (e.g. Herget-Rosenthal et al., 2007). However, the absence of differences in uric acid values would not support this idea (i.e. high uric acid levels are often indicative of kidney failure in birds; Hochleithner, 1994).

Males fed on fuel oil showed higher AST activities than control males. Several studies on seabirds suffering from longterm exposures to oil spills show an increase of AST activities. Thus, pigeon guillemots captured in areas affected by the ExxonValde $z$ oil spill seven years earlier showed higher AST activities than birds from non-affected areas (Seiser et al., 2000; Golet et al., 2002). Similarly, yellow-legged gulls from oiled areas showed higher AST activities 17 months after the spill, AST being also positively correlated to TPAH levels in blood (AlonsoAlvarez et al., 2007). However, avian studies on the effects of an acute exposure to oil spills on AST activities are not so consistent. Thus, whereas pigeon guillemots fed with crude oil did not show significant changes on AST activities (Prichard et al., 1997), in American coots AST activities decreased after the birds had suffered plumage oiling and ingested large amount of crude oil (Newman et al., 2000). Therefore, acute and chronic longterm exposures could result in different responses. Interestingly, females did not show significant differences in AST levels. Both groups showed high AST activities similar to those of P-males, suggesting that control females display higher hepatic damages than males from chronic oil exposure. In that scenario, the experimental increase of toxic compounds present in fuel oil over that threshold would have not been able to raise the AST production in females. On the other hand, females, but not males, showed a positive correlation between AST activities and the days feeding (females: $r=+0.52, p=0.040$; males: $r=0.06, p=0.85$ ). Since fuel oil was only restricted to the first seven days, this result can be associated to a stronger sensitivity of females than males to feeding on vegetable oil.

We have previously reported higher GGT activities in female, but not male, yellow-legged gulls from oiled areas after the Prestige oil spill (Alonso-Alvarez et al., 2007). Here, females were again the affected sex. Interestingly, the pattern was now reversed. Control females showed higher GGT activities than 
P-females. Although a decrease in GGT activity after fuel oil exposure seems contraintuitive, decreased GGT levels after acute exposure to some toxic compounds (i.e. PCBs) has been reported in mice (Hori et al., 1997). Moreover, a decrease in GGT activity has been also described in mussels (Mytilus edulis) experimentally exposed to PAHs (Krishnakumar et al., 1997). An alternative interpretation would be that P-females would have not been able to increase GGT activity in response to some physiological requirement such as $\mathrm{C}$-females did. In female mallards, serum GGT activity increased 20-fold during the egg-laying period (Fairbrother et al., 1990). Interestingly, the time elapsed from the date of clutch end to the blood sampling was inversely related to GGT values in females $(r=-0.55, p=0.029)$, but not in males $(r=0.37, p=0.244)$. This suggests that healthy females were able to increase GGT activity as a response to the physiological requirements of egg-laying (e.g. Christians and Williams, 1999; Barboza and Jorde, 2002). Overall, the results indicate a sex-related sensitivity of GGT and AST enzymes to acute oil exposures.

Sex-specific effects of oil contamination on seabirds have been rarely explored, and their demographic consequences are commonly ignored. A recent study indicated that when femaleskewed mortality occurs, a large decrease in breeding numbers is expected, because unmated males can defer breeding (MartínezAbraín et al., 2006), and this may in part explain the considerable decline observed in oiled colonies after oil spills (Velando et al., 2005b). Sex-related sensitivity to fuel oil, such as reported in this study, could be affecting the population dynamics and constrains the recovery of gulls in oil-affected colonies. Unfortunately, the lack of an appropriate monitoring of yellow-legged gull populations (especially before the Prestige event) has prevented to obtain definitive conclusions at least to the present time. Gulls are long-lived birds (e.g. Annett and Pierotti, 1999) and hence delayed effects such as reduced lifespan or reduced offspring fecundity could arise in future years. Nonetheless, the study of another seabird sharing the same colonies as gulls (the European shag; Phalacrocorax aristotelis) has reported a clear negative impact in terms of population growth rate and breeding success (Velando et al., 2005a). Thus, further investigation is still necessary to disentangle the long-term effects of the oil spill on the gull population.

In summary, several findings of the present experiment corroborate the correlational results of a previous study, which suggested sub-lethal effects derived from long-term exposures to fuel oil in the same seabird species (Alonso-Alvarez et al., 2007). Meanwhile, the study also revealed different patterns in aminotransferases, probably an adaptive response to endure the acute short-term exposure to fuel oil. Since the yellow-legged gull belongs to a complex of species widely distributed throughout the Northern hemisphere (e.g. Liebers et al., 2001, 2004), the results as a whole might provide a tool for future evaluations of short- and long-term effects of oil spills in seabirds. Decreased glucose and inorganic phosphorus levels in plasma are expected in both short- and long-lasting exposures to fuel oil, whereas different responses of AST and GGT are expected depending on both the sex of the individuals and the temporal pattern of exposure.

\section{Acknowledgements}

We acknowledge Xunta de Galicia staff (Spain) and Naviera Mar de Ons for providing us with logistic support during the sampling campaigns. We are grateful to Rafael Mateo and Lorenzo Perez-Rodriguez for their support in spectrophotometry. We also acknowledge Marta Lopez-Alonso for her logistic support in the HPLC analyses and Carmen Díez and Julio Eiroa for field assistance. C.A.-A. and A.V. were supported by a Ramon y Cajal Fellowship (Ministerio de Educación y Ciencia, Spain). The present study was founded by the program Plan Nacional I+D+I 2004-2007 (Ministerio de Educación y Ciencia, Spain).

\section{References}

Alonso-Alvarez, C., 2001. Effects of testosterone implants on pair behaviour during incubation in the Yellow-legged Gull Larus cachinnans. J. Avian Biol. 32, 326-332.

Alonso-Alvarez, C., 2005. Age dependent changes in plasma biochemistry of yellow-legged gulls (Larus cachinnans). Comp. Biochem. Physiol. A 140, 512-518.

Alonso-Alvarez, C., Ferrer, M., 2001. A biochemical study about fasting, subfeeding and recovery processes in yellow-legged gulls. Physiol. Biochem. Zool. 74, 703-713.

Alonso-Alvarez, C., Velando, A., 2001. Effect of testosterone on the behaviour of yellow-legged gulls (Larus cachinnans) in a high-density colony during the courtship period. Ethol. Ecol. Evol. 13, 341-349.

Alonso-Alvarez, C., Munilla, I., López, M., Velando, A., 2007. Sublethal toxicity of the Prestige oil spill on yellow-legged gulls. Environ. Int. 33, $773-781$.

Alonso-Alvarez, C., Velando, A., 2003. Female body condition and brood sex ratio in yellow-legged gull Larus cachinnans. Ibis 145, 220-226.

Annett, C.A., Pierotti, R., 1999. Long-term reproductive output in Western Gulls: consequences of alternate tactics in diet choice. Ecology 80, 288297

Balseiro, A., Espi, A., Marquez, I., Perez, V., Ferreras, M.C., Marin, J.F.G., Prieto, J.M., 2005. Pathological features in marine birds affected by the Prestige's oil spill in the north of Spain. J. Wildlife Dis. 41, 371-378.

Barboza, P.S., Jorde, D.G., 2002. Intermittent fasting during winter and spring affects body composition and reproduction of a migratory duck. J. Comp. Physiol. B 172, 419-434.

Barron, M.G., Podrabsky, T., Ogle, S., Ricker, R.W., 1999. Are aromatic hydrocarbons the primary determinant of petroleum toxicity to aquatic organisms? Aquat. Toxicol. 46, 253-268.

Booth, A.M., Sutton, P.A., Lewis, C.A., Lewis, A.C., Scarlett, A., Chau, W., Widdows, J., Rowland, S.J., 2007. Unresolved complex mixtures of aromatic hydrocarbons: thousands of overlooked persistent, bioaccumulative, and toxic contaminants in mussels. Environ. Sci. Technol. 41, 457-464.

Bosch, M., 1996. Sexual size dimorphism and determination of sex in yellowlegged gulls. J. Field Ornithol. 67, 534-541.

Bosch, X., 2003. Exposure to oil spill has detrimental effect on cleanup workers' health. Lancet 361, 147.

Brugère-Picoux, J., Brugère, H., Basset, I., Sayad, N., Vaast, J., Michaux, J.M., 1987. Biochemie clinique en pathologie aviaire. Introit et limites des dosages enzymatiques chez la poule. Rec. Med. Vet. 163, 1091-1099.

Butler, R.G., Lukasiewicz, P., 1979. A field study of the effect of crude oil on Herring gull (Larus argentatus) chick growth. Auk 96, 809-812.

Camphuysen, C.J., Heubeck, M., Cox, S.L., Bao, R., Humple, D., Abraham, C., Sandoval, A., 2002. The Prestige oil spill in Spain. Atlant. Seabirds 4, 131-140.

Castellini, M.A., Rea, L.D., 1992. The biochemistry of natural fasting at its limits. Experientia 48, 575-582.

Christians, J.K., Williams, T.D., 1999. Organ mass dynamics in relation to yolk precursor production and egg formation in European starlings Sturnus vulgaris. Physiol. Biochem. Zool. 72, 455-461. 
CSIC (Consejo Superior de Investigaciones Científicas), 2003. CSIC technical reports No. 01 and 02 (in Spanish). http://csicprestige.iim.csic.es/ Informes.htm.

Diez, S., Jover, E., Bayona, J.M., Albaides, J., 2007. Prestige oil spill. III. Fate of a heavy oil in the marine environment. Environ. Sci. Technol. 41, 3075-3082.

Fairbrother, A., Craig, M.A., Walker, K., O'Loughlin, D., 1990. Changes in mallard (Anas platyrhynchos) serum chemistry due to age, sex and reproductive condition. J. Wildlife Dis. 26, 67-77.

Fernandez, N., Cesar, A., Gonzalez, M., DelValls, T.A., 2006a. Level of contamination in sediments affected by the Prestige oil spill and impact on the embryo development of the sea urchin. Cienc. Mar. 32, 421-427.

Fernandez, N., Cesar, A., Salamanca, M.J., DelValls, T.A., 2006b. Toxicological characterisation of the aqueous soluble phase of the Prestige fuel-oil using the sea-urchin embryo bioassay. Ecotoxicology 15, 593-599.

García-Berthou, E., 2001. On the misuse of residuals in ecology: testing regression residual $v s$. the analysis of covariance. J. Anim. Ecol. 70, 708-711.

Gelboin, H.V., Ts'o, P.O.P., 1981. Polycyclic Hydrocarbons and Cancer, vol. 3. Academic Press, New York.

Golet, G.H., Seiser, P.E., McGuire, A.D., Roby, D.D., Fischer, J.B., Kuletz, K.J., Irons, D.B., Dean, T.A., Jewett, S.C., Newman, S.H., 2002. Long-term direct and indirect effects of the Exxon Valdez oil spill on pigeon guillemots in Prince William Sound, Alaska. Mar. Ecol. Prog. Ser. 241, 287-304.

Gorsline, J., Holmes, W.N., 1982. Suppression of adrenocortical activity in mallard ducks exposed to petroleum-contaminated food. Arch. Environ. Contam. Toxicol. 11, 497-502.

Harr, K.E., 2002. Clinical chemistry of companion avian species: a review. Vet. Clin. Pathol. 31, 140-151.

Herget-Rosenthal, S., Bokenkamp, A., Hofmann, W., 2007. How to estimate GFR-serum creatinine, serum cystatin C or equations? Clin. Biochem. 40, 153-161.

Hochleithner, M., 1994. Biochemistries. In: Ritchie, B.W., Harrison, G.H., Harrison, L.R. (Eds.), Avian Medicine: Principles and Application. Wingers Publishing, Lake Worth, pp. 223-245.

Hori, M., Kondo, H., Ariyoshi, N., Yamada, H., Hiratsuka, A., Watabe, T., Oguri, K., 1997. Changes in the hepatic glutathione peroxidase redox system produced by coplanar polychlorinated biphenyls in Ah-responsive and -less-responsive strains of mice: mechanism and implications for toxicity. Environ. Toxicol. Pharmacol. 3, 267-275.

Hoyt, D.F., 1979. Practical methods of estimating volume and fresh weight of bird eggs. Auk 96, 73-77.

Keith, L.H., Telliard, W.A., 1979. Priority pollutants. I. A perspective view. Environ. Sci. Technol. 13, 416-423.

Kertesz, V., Hlubik, I., 2002. Plasma ALP activity and blood PCV value changes in chick fetuses due to exposure of the egg to different xenobiotics. Environ. Pollut. 117, 323-327.

Krishnakumar, P.K., Casillas, E., Varanasi, U., 1997. Cytochemical responses in the digestive tissue of Mytilus edulis complex exposed to microencapsulated PAHs or PCBs. Comp. Biochem. Physiol. C 118, 11-18.

Laffon, B., Rabade, T., Pasaro, E., Mendez, J., 2006. Monitoring of the impact of Prestige oil spill on Mytilus galloprovincialis from Galician coast. Environ. Int. 32, 342-348.

Leighton, F.A., Lee, Y.Z., Rahimtula, A.D., O’Brien, P.J., Peakall, D.B., 1985. Biochemical and functional disturbances in red blood cells of herring gulls ingesting Prudhoe Bay crude oil. Toxicol. Appl. Pharmacol. 81, 25-31.

Lewandowski, A.H., Campbell, T.W., Harrison, G.J., 1986. Clinical chemistries. In: Harrison, G.J., Harrison, L.R. (Eds.), Clinical Avian Medicine and Surgery. Saunders, Philadelphia, pp. 192-200.

Liebers, D., Helbig, A.J., De Knijff, P., 2001. Genetic differentiation and phylogeography of gulls in the Larus cachinnans-fuscus group (Aves: Charadriiformes). Mol. Ecol. 10, 2447-2462.

Liebers, D., de Knijff, P., Helbig, A.J., 2004. The herring gull complex is not a ring species. Proc. R. Soc. Lond. B 271, 893-901.
Marcos, M.J., Aguero, A., Garcia-Olivares, A., Haupt, B.J., De Pablos, J.L., 2004. Assessment of the behaviour of oil in the tanks of the "Prestige" in the Atlantic deep sea. Sci. Mar. 68, 307-315.

Martínez-Abraín, A., Velando, A., Genovart, M., Gerique, C., Bartolomé, M.A., Villuendas, E., Sarzo, B., Oro, D., 2006. Sex-specific mortality of European shags during an oil spill: demographic implications for the recovery of colonies. Mar. Ecol. Progr. Ser. 318, 271-276.

Morales-Caselles, C., Jiménez-Tenorio, N., Gonzalez de Canales, M.L., Sarasquete, C., DelValls, T.A., 2006. Ecotoxicity of sediments contaminated by the oil spill associated with the tanker Prestige using juveniles of the fish Sparus aurata. Arch. Environ. Contam. Toxicol. 51, 652-660.

Newman, S.H., Mazet, J.K., Ziccardi, M.H., Lieske, C.L., Fauquier, D.A., Gardner, I.A., Zinkl, J.G., Christopher, M.M., 1999. Haematological changes and anaemia associated with captivity and petroleum exposure in seabirds. Comp. Hematol. Int. 9, 60-67.

Newman, S.H., Anderson, D.W., Ziccardi, M.H., Trupkiewicz, J.G., Tseng, F.S., Christopher, M.M., Zinkl, J.G., 2000. An experimental soft-release of oilspill rehabilitated American coots (Fulica americana): II. Effects on health and blood parameters. Environ. Pollut. 107, 295-304.

Nicolas, J.M., 1999. Vitellogenesis in fish and the effects of polycyclic aromatic hydrocarbon contaminants. Aquat. Toxicol. 45, 77-90.

Ordas, M.C., Albaines, J., Bayona, J.M., Ordas, A., Figueras, A., 2007. Assessment of in vivo effects of the prestige fuel oil spill on the Mediterranean mussel immune system. Arch. Environ. Contam. Toxicol. 52, 200-206.

Pérez, C., Velando, A., Domínguez, J., 2006. Parental food conditions influence sex-specific embryo mortality in the yellow-legged gull (Larus michahellis). J. Ornithol. 147, 513-519.

Peterson, C.H., 2001. The Exxon Valdez oil spill in Alaska: acute, indirect and chronic effects on the ecosystem. Adv. Mar. Biol. 39, 1-103.

Prichard, A.K., Roby, D.D., Bowyer, R.T., Duffy, L.K., 1997. Pigeon guillemots as a sentinel species: a dose-response experiment with weathered oil in the field. Chemosphere 35, 1531-1548.

Reynaud, S., Deschaux, P., 2006. The effects of polycyclic aromatic hydrocarbons on the immune system of fish: a review. Aquat. Toxicol. 77, 229-238.

SAS Institute, 2001. SAS/STAT Software: changes and enhancements, version 8.2. SAS Publishing, North Carolina.

Seiser, P.E., Duffy, L.K., McGuire, A.D., Roby, D.D., Golet, G.H., Litzow, M.A., 2000. Comparison of pigeon guillemot, Cepphus columba, blood parameters from oiled and unoiled areas of Alaska eight years after the Exxon Valdez oil spill. Mar. Pollut. Bull. 40, 152-164.

Stevens, L., 1996. Avian Biochemistry and Molecular Biology. Cambridge University Press, Cambridge.

Stevenson, R.D., Woods, W.A., 2006. Condition indices for conservation: new uses for evolving tools. Int. Comp. Biol. 46, 1169-1190.

Still, A.W., 1982. On the numbers of subjects used in animal behaviour experiments. Anim. Behav. 30, 873-880.

Stubblefield, W.A., Hancock, G.A., Prince, H.H., Ringer, R.K., 1995. Effects of naturally weathered Exxon-Valdez crude-oil on mallard reproduction. Environ. Toxicol. Chem. 14, 1951-1960.

Velando, A., Álvarez, D., Mouriño, J., Arcos, F., Barros, A., 2005a. Population trends and reproductive success of European shag following the Prestige oil spill in the Iberian Peninsula. J. Ornithol. 146, 116-120.

Velando, A., Munilla, I., Leyenda, P.M., 2005b. Short-term indirect effects of the Prestige oil spill on a marine top predator: changes in prey availability for European shags. Mar. Ecol. Progr. Ser. 302, 263-274.

Viñas-Diéguez, L., 2002. Evaluación de hidrocarburos aromáticos policíclicos (HAPs) por cromatografía líquida de alta eficacia (CLAE) en el entorno marino gallego. PhD Thesis dissertation (in Spanish). Universidade de Vigo, Vigo, Spain

Whittow, G.C., 2000. Sturkie's Avian Physiology. Academic Press, London.

Wyss, M., Kaddurah-Daouk, R., 2000. Creatine and creatinine metabolism. Physiol. Rev. 80, 1107-1213. 